\title{
THE MODEL OF DEMAND AND INVENTORY IN A DECLINE PHASE OF THE PRODUCT LIFE CYCLE
}

Piotr Hachuła, M.Sc.

Institute of Logistics and Warehousing, Logistics Expertise Department

Estkowskiego 6, 61-755 Poznań, Poland

e-mail: Piotr.Hachuta@gmail.com

Prof. Ewa Schmeidel

University of Biatystok, Institute of Mathematics

Ciolkowskiego 1M, 15-245 Biatystok, Poland

e-mail:eschmeidel@math.uwb.edu.pl

Received 21 August 2015, Accepted 27 June 2016

\begin{abstract}
In the paper, the mathematical model of demand and inventory is studied from the perspective of its applications in real business cases. The model is formulated with three difference equations of first order. Three scenarios focused on the last phase of the product life cycle, a decline, are investigated and commented upon.
\end{abstract}

Keywords: demand, inventory, mathematical model, product life cycle, supply chain

JEL classification: C32, D24 


\section{Introduction}

\section{Inventory management}

Many methods of forecasting or inventory level calculations have been formulated and analysed in the mid of the 20th century. They have come up as a response to the companies' needs related to the huge economy growth in the western countries after the World War II. The works of Metzlar (Metzlar, 1941), Wagner and Within (Wagner, Within, 1958), and Brown (Brown, 1959) can be treated as pioneer ones in those areas. The properties of the methods proposed, and the possibilities of their applications in real-life cases have been studied so far on the background of several branches of mathematics: operations research, control theory, dynamical programming, difference and differential equations, and dynamical systems.

\section{Inventory}

Krzyżaniak and Cyplik (Krzyżaniak, Cyplik, 2008) define stock as a given amount of goods considered in a logistics system (company, supply chain), which are stored and not used immediately, but are devoted for further processing or sales. Those goods can be precisely indicated by localization (storage place), and their amount can be expresses by either quantities or values. Inventory keeping is necessary, since many conditions, e.g. time constrains in production or delivery, availability constraints, etc., make satisfying of demand basing on production or purchase not possible at any required time. In most cases, the expected time of fulfilling an order is shorter than the total time of a company reaction. In other words, the time needed for producing and delivering the required goods is longer than the time in which a customer demand can be satisfied. One of ways to eliminate the difference between those times, the so called time-gap, is keeping stock. Setting an optimal stock level, optimal order quantity, and optimal order frequency is a main task of the inventory management process. To become more familiar with these methods and rules, one can refer to Krzyżaniak, Cyplik (2008), and Sarjusz-Wolski (2000).

\section{Demand}

Demand is defined by Krzyżaniak and Cyplik (Krzyżaniak, Cyplik, 2008) as a need of certain amount, or a quantity of a given good. It is placed at a company by a customer with agreed fixed conditions, e.g. a price. Demand depends on many factors such as a price, customers' income, possible substitution by other goods, economy or political situation, and many others. For the sake of demand modelling, one sets a dependence of the demand on a few chosen factors. In this paper, we consider the dependence on one defined factor - a price. Based 
on such assumption, it can be said that a company can influence the demand by changing a price. Since inventory is obviously related to the demand, it can be stated that price changes influence a stock level as well, what will be shown later in this paper.

\section{Product life cycle}

Let us assume that there is one good (a product) available in the market. The time of its presence in the market is called the product life. There are a few phases that can be observed during the product life: introduction, growth, maturity, and decline. Those phases constitute the product life cycle (Iskra, Woźniak, 2014). The phases can be distinguished by the values of sales and profit. Figure 1 depicts the sales and profit depending on the phase of the product life cycle. The proper assessment of the current phase allows to plan the future activities related to a product, set a strategy, and manage the inventory optimally. The latter - an inventory - is analysed in this paper from the perspective of the product whose stock is intended to be limited at a certain level. Such a case can represent the phase of a decline of the product life cycle.

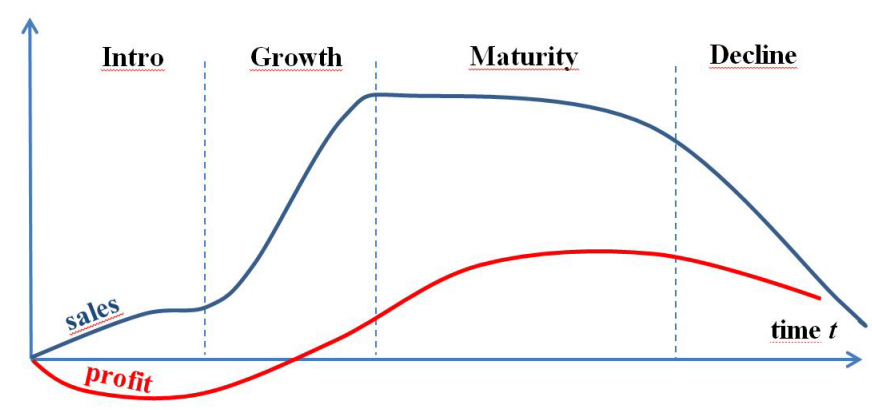

Figure 1. Product life cycle

Source: own elaboration based on Iskra, Woźniak (2014).

\section{Mathematical model}

The model describes a supply chain that consists of customers, a retailer, and a manufacturer.

The following rules apply:

- customers buy a good from a retailer,

- customer demand depends on a retail price,

- the retailer orders a good according to the forecast dependent on the sales and forecast in a previous period, 
- a manufacturer produces and delivers the exact ordered amount; the production capacity is unlimited,

- the retailer can offer a discount depending on stock - when stock is high, the retailer offers a discount to encourage customers to make a purchase.

The process is deterministic, based on fixed rules and formulas, and is automatically repeated in the next period.

The change of stock is a difference between the receipt amount that had been ordered in the previous period, and the sold amount. In the mathematical form that is:

$$
S_{t+1}=Z_{t+1}+S_{t}-D_{t}
$$

where:

$S_{t}-$ stock in the period $t$,

$D_{t}$ - customers' demand at time $t$,

$Z_{t+1}$ - retailer's order placed at the manufacturer at time $t$ to be realized at $t+1$ as a delivery of the amount $P_{t+1}$.

It is necessary to note that stock $S_{t+1}$ is measured after the delivery receipt $P_{t+1}=Z_{t+1}$, but before the sales of amount $D_{t+1}$. Only the sales $\mathrm{Dt}$ from the previous period are taken into account. That implies that the demand $D_{t+1}$ can be satisfied directly from the delivery $Z_{t+1}$. Inventory $S_{t}$ can be negative. Such situation can happen when the demand is not satisfied.

\section{Example}

$S_{0}=0$, forecast and delivery $Z_{1}=10$, but real demand $D_{0}=20$. Then $S_{1}=-10$ means that 10 units are missing to satisfy the customers' demand. The retailer forecasts the demand using a single exponential smoothing model introduced by Brown (Brown, 1959). The forecast of demand at time $\mathrm{t}$ is expressed with the following formula:

$$
D_{t+1}^{\prime}=\alpha D_{t}+(1-\alpha) D_{t}^{\prime}, 0 \leqslant \alpha \leqslant 1
$$

where:

$D_{t}^{\prime}-$ forecast of demand at time $t$,

$\alpha-$ a parameter to define how fast the actuals of real demand are reflected in the forecast.

For $\alpha=1$ demand forecast $D_{t}^{\prime}$ is equal to real demand $D_{t-1}$ at the previous period. When $\alpha=0: D_{t}^{\prime}=D_{t-1}^{\prime}$, which means that real demand does not influence the forecast.

The assumption of the infinite capacity of production yields: $P_{t}=Z_{t}=D_{t}^{\prime}$; hence 


$$
S_{t+1}=D_{t+1}^{\prime}+S_{t}-D_{t}
$$

There is a fixed parameter $T>0$ representing target stock. If stock $S_{t}$ is greater than $T$, the retailer considers it as an excess, and offers a discount in order to decrease stock. The indicator of excess stock is calculated as:

$$
v_{t}=\frac{S_{t}-T}{T}
$$

There can be a discount set in order to increase the customer demand, and, by that, to decrease stock. It is important to notice that the discount value is calculated for every single period, valid for one period, and calculated again in the next period based on new stock. The dependence between the excess stock indicator and discount indicator is formulated as follows:

$$
r_{t}=\frac{v_{t}}{q}
$$

where $q$ is a constant, $q>0$. When $v_{t+1}$ increases, then the discount indicator increases as well. Let us assume that demand depends only on a price of the offered good. The price can be changed arbitrarily from one value to another (i.e. from $p_{0}$ to $p_{1}$ ). Let the relative change of the price be denoted as:

$$
\delta p_{t+1}=\frac{p_{t+1}}{p_{t}}
$$

The change of the price influences the demand according to the following formula:

$$
D_{t+1}=\left(\delta p_{t+1}\right)^{-2 c} D_{t}
$$

where $c>0$ is a price elasticity coefficient.

The price can also be changed by offering a discount $r_{t}$ related to stock and target stock. Such a discount influences the demand directly according to the formula:

$$
D_{t+1}=\frac{D_{t}}{\left(1-r_{t+1} / a\right)^{k}}
$$

where $a$ is the upper bound of a discount, and $0<k<1$ is a parameter similar to the price elasticity coefficient $c$, but related to the discount.

If there is no discount offered and the price is not changed, then the customers' demand $D_{t}$ remains unchanged as well. The discount and price change cause demand changes according to the above quoted formulas. 
From (2-3), and (7-8) we obtain that the demand can be expressed as:

$$
D_{t+1}=\frac{\left(\delta p_{t}\right)^{-2 c} D_{t}}{\left(1-r_{t+1} / a\right)^{k}}
$$

Using (4) and (5) we obtain:

$$
D_{t+1}=\frac{(q a T)^{k}\left(\delta p_{t}\right)^{-2 c} D_{t}}{\left[(q a+1) T-S_{t+1}\right]^{k}}
$$

Eventually, the model is expressed by a system of three first order difference equations:

$$
\left\{\begin{array}{c}
D_{t+1}=\frac{(q a T)^{k}\left(\delta p_{t}\right)^{-2 c} D_{t}}{\left[(q a+1) T-S_{t+1}\right]^{k}} \\
S_{t+1}=D_{t+1}^{\prime}+S_{t}-D_{t} \\
D_{t+1}^{\prime}=\alpha D_{t}+(1-\alpha) D_{t}^{\prime}
\end{array}\right.
$$

It can be noticed that parameters $a$ and $q$ always appear together. Hence, from the mathematical point of view, they could be replaced by one parameter. Similarly, the parameters $k$ and $c$, as influencing the same factor - change of a price - could be potentially unified.

\section{Simulations}

Several simulations have been performed with various initial values of variables and various parameters. To simplify the analysis, assumption $\left(\delta p_{t}\right)^{2 c}=1$ for every $t$ have been made. It means, that the demand is controlled only with the discount offered according to (8), and not with arbitrary price changes.

The results are presented in the following sections. To make the analysis more tangible and realistic, we assume that $t$ relates to a week, observations are made in a period of a year, i.e. $\mathrm{t}_{\max }=52$, and the price is expressed in Polish Zloty (PLN, further denoted as “ $\mathrm{zl}$ ”).

\section{Simulation no. 1}

This simulation recalls the scenario described by Ma and Feng (Ma, Feng, 2008), so the input data are taken directly from there, and they are presented in Table 1. The results are presented in Figure 2 and Table 2. 
Table 1. Input data for simulation no. 1

\begin{tabular}{|c|c|c|}
\hline \multirow{4}{*}{ Initial conditions } & $S_{0}=$ & 1,000 \\
\hline & $D_{0}^{\prime}=$ & 0 \\
\hline & $D_{0}=$ & 500 \\
\hline & $p_{0}=p_{t}=$ & 100 \\
\hline \multirow{5}{*}{ Parameters } & $T=$ & 600 \\
\hline & $\alpha=$ & 0.82 \\
\hline & $a=$ & 0.7 \\
\hline & $q=$ & 1.2 \\
\hline & $k=$ & 0.11 \\
\hline
\end{tabular}

Source: own elaboration basing on Ma, Feng (2008).

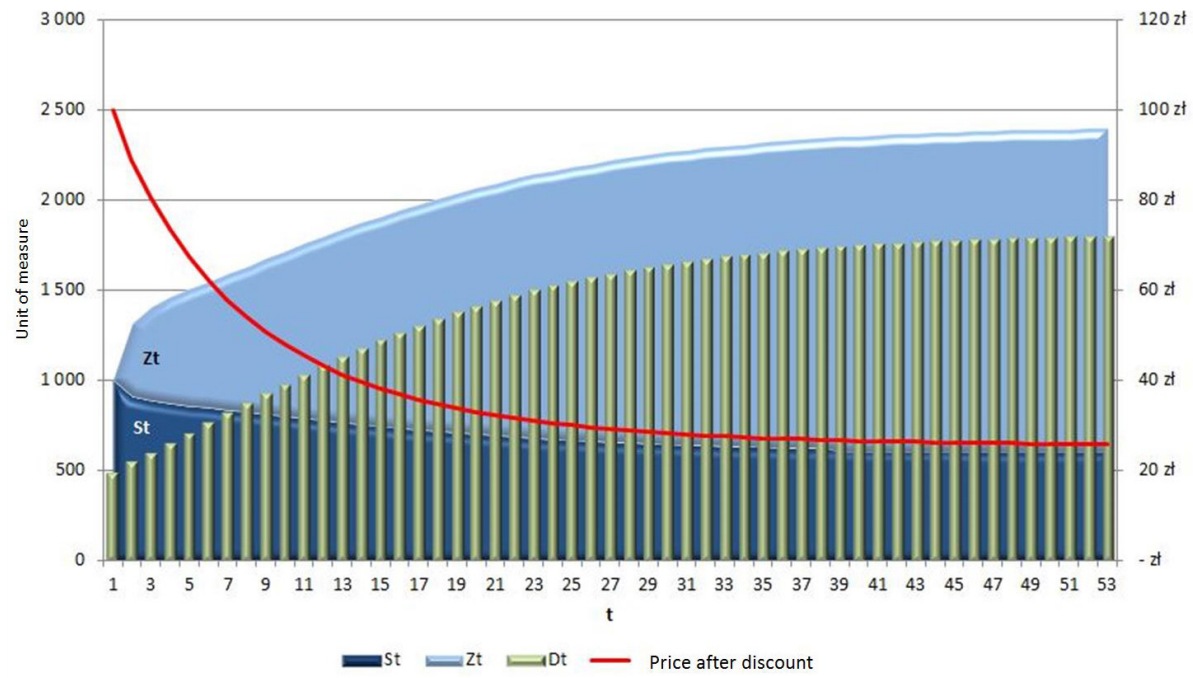

Figure 2. Graphical results of Simulation no. 1

Source: own elaboration basing on Ma, Feng (2008).

\section{Comment}

It can be observed that the stock St converges to the set amount $T=600$ thanks to a price decrease, and, as a consequence, the demand increases. We have to underline that the demand increases more than three times, but this is on the expense of a great discount - the price reaches the level of about $25 \%$ of the initial one. This suggests a careful approach and the need of running a detailed economic analysis before applying such a solution. 


\section{Simulation no. 2 - change of product version and sell-out of current version}

An essential change versus simulation no. 1 is setting the target stock parameter $T=1$. It reflects a real business case when a retailer wants to sell out the stock of a good. In this case, stock $S_{0}=1000$ exceeds significantly the recently recorded demand $D_{0}=10 . T$ is set to 1 as the first integer satisfying $T>0$. Parameters $a, q$, and $k$ must be set carefully, in order to assure that the right-hand side of equation (10) is a real number. That will be true when $\left(S_{t}-T\right) / \mathrm{T}<a q$ or when $k$ as a degree of a root is an odd number.

The set of initial values and parameters is presented in Table 3, and the results - in Figure 3 and in Table 4.

Table 2. Numerical results of simulation no. 1

\begin{tabular}{|c|c|c|c|c|c|c|c|c|}
\hline$t$ & $D_{t}^{\prime}$ & $Z_{t}$ & $S_{t}$ & $D_{t}$ & $\begin{array}{l}\text { Coefficient } \\
1 /\left(1-r_{t} / a\right)^{k}\end{array}$ & $\begin{array}{c}\text { Discount } \\
(\%)\end{array}$ & $\begin{array}{c}\text { Cumulated } \\
\text { discount } \\
(\%)\end{array}$ & $\begin{array}{c}\text { Price after } \\
\text { discount } \\
\text { (PLN) }\end{array}$ \\
\hline 0 & 0.0 & 0.0 & $1,000.0$ & 500.0 & & 0.0 & & 100.0 \\
\hline 1 & 410.0 & 410.0 & 910.0 & 555.4 & 1.111 & 11.1 & 11.1 & 88.9 \\
\hline 2 & 529.2 & 529.2 & 883.8 & 608.3 & 1.095 & 9.5 & 19.6 & 80.4 \\
\hline 3 & 594.1 & 594.1 & 869.6 & 661.8 & 1.088 & 8.8 & 26.6 & 73.4 \\
\hline 4 & 649.6 & 649.6 & 857.4 & 715.9 & 1.082 & 8.2 & 32.6 & 67.4 \\
\hline 5 & 704.0 & 704.0 & 845.5 & 770.5 & 1.076 & 7.6 & 37.8 & 62.2 \\
\hline 6 & 758.5 & 758.5 & 833.5 & 825.1 & 1.071 & 7.1 & 42.2 & 57.8 \\
\hline 7 & 813.1 & 813.1 & 821.5 & 879.3 & 1.066 & 6.6 & 46.0 & 54.0 \\
\hline 8 & 867.4 & 867.4 & 809.6 & 932.9 & 1.061 & 6.1 & 49.3 & 50.7 \\
\hline 9 & 921.1 & 921.1 & 797.8 & 985.4 & 1.056 & 5.6 & 52.1 & 47.9 \\
\hline 10 & 973.9 & 973.9 & 786.2 & $1,036.7$ & 1.052 & 5.2 & 54.6 & 45.4 \\
\hline 11 & $1,025.4$ & $1,025.4$ & 774.9 & $1,086.5$ & 1.048 & 4.8 & 56.8 & 43.2 \\
\hline 12 & $1,075.5$ & $1,075.5$ & 763.9 & $1,134.5$ & 1.044 & 4.4 & 58.7 & 41.3 \\
\hline 13 & $1,123.9$ & $1,123.9$ & 753.3 & $1,180.7$ & 1.041 & 4.1 & 60.4 & 39.6 \\
\hline 14 & $1,170.5$ & $1,170.5$ & 743.1 & $1,224.9$ & 1.037 & 3.7 & 61.9 & 38.1 \\
\hline 50 & $1,793.0$ & $1,793.0$ & 606.4 & $1,796.1$ & 1.001 & 0.1 & 74.2 & 25.8 \\
\hline 51 & $1,795.5$ & $1,795.5$ & 605.9 & $1,798.4$ & 1.001 & 0.1 & 74.2 & 25.8 \\
\hline 52 & $1,797.9$ & $1,797.9$ & 605.3 & $1,800.5$ & 1.001 & 0.1 & 74.2 & 25.8 \\
\hline
\end{tabular}

Source: own elaboration. 
Table 3. Input data for simulation no. 2

\begin{tabular}{|c|c|c|}
\hline \multirow{4}{*}{ Initial conditions } & $S_{0}=$ & 1,000 \\
\hline & $D_{0}^{\prime}=$ & 0 \\
\hline & $D_{0}=$ & 10 \\
\hline & $p_{0}=p_{t}=$ & 100 \\
\hline \multirow{5}{*}{ Parameters } & $T=$ & 1 \\
\hline & $\alpha=$ & 0.82 \\
\hline & $a=$ & 0.7 \\
\hline & $q=$ & $1,428.0$ \\
\hline & $k=$ & \begin{tabular}{|l|l|} 
\\
\end{tabular} \\
\hline
\end{tabular}

Source: own elaboration.

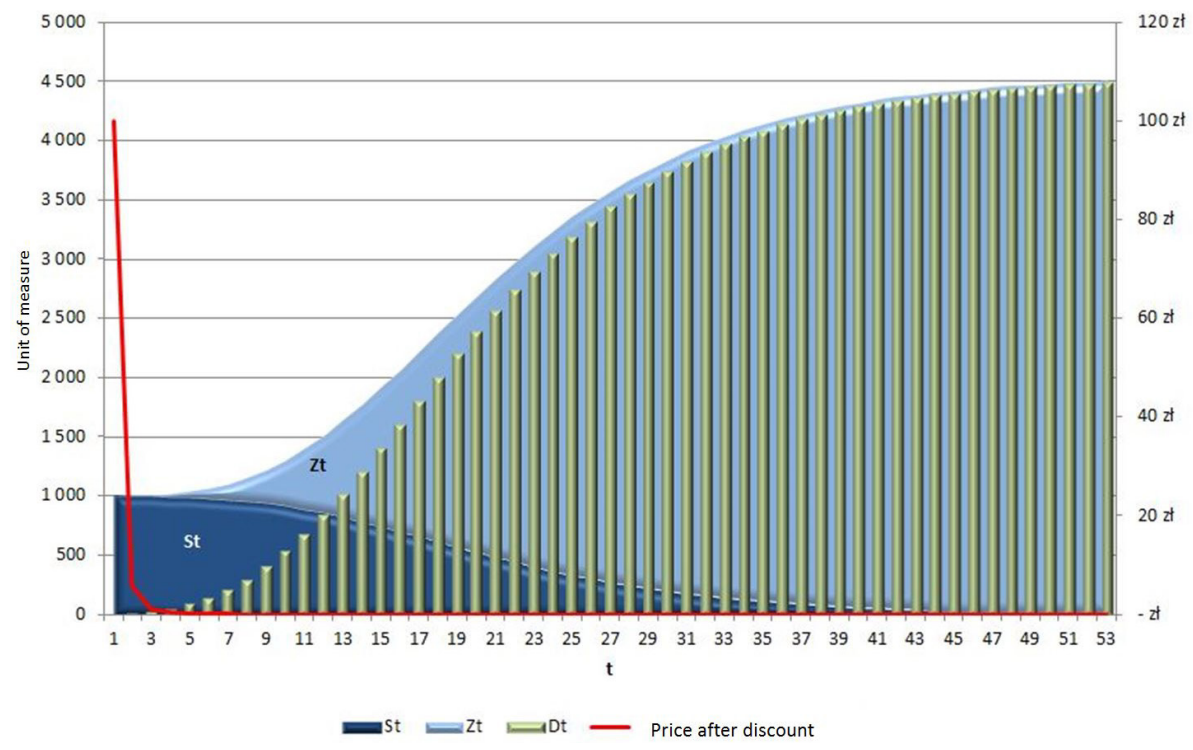

Figure 3. Graphical results of Simulation no. 2

Source: own elaboration. 
Table 4. Numerical results of simulation no. 2

\begin{tabular}{|c|c|c|c|c|c|c|c|c|}
\hline$t$ & $D_{t}^{\prime}$ & $Z_{t}$ & $S_{t}$ & $D_{t}$ & $\begin{array}{l}\text { Coefficient } \\
1 /\left(1-r_{t} / a\right)^{k}\end{array}$ & $\begin{array}{c}\text { Discount } \\
(\%)\end{array}$ & $\begin{array}{c}\text { Cumulated } \\
\text { discount } \\
(\%)\end{array}$ & $\begin{array}{c}\text { Price after } \\
\text { discount } \\
\text { (PLN) }\end{array}$ \\
\hline 0 & 0.0 & 0.0 & $1,000.0$ & 10.0 & & 0.0 & & 100.0 \\
\hline 1 & 8.2 & 8.2 & 998.2 & 19.0 & 1.900 & 90.0 & 90.0 & 10.0 \\
\hline 2 & 17.1 & 17.1 & 996.3 & 35.8 & 1.883 & 88.3 & 98.8 & 1.2 \\
\hline 3 & 32.4 & 32.4 & 992.9 & 66.4 & 1.855 & 85.5 & 99.8 & 0.2 \\
\hline 4 & 60.3 & 60.3 & 986.8 & 120.2 & 1.811 & 81.1 & 100.0 & 0.0 \\
\hline 5 & 109.4 & 109.4 & 976.0 & 209.8 & 1.745 & 74.5 & 100.0 & 0.0 \\
\hline 6 & 191.7 & 191.7 & 957.9 & 348.4 & 1.661 & 66.1 & 100.0 & 0.0 \\
\hline 7 & 320.2 & 320.2 & 929.7 & 545.5 & 1.566 & 56.6 & 100.0 & 0.0 \\
\hline 8 & 504.9 & 504.9 & 889.2 & 802.4 & 1.471 & 47.1 & 100.0 & 0.0 \\
\hline 9 & 748.9 & 748.9 & 835.6 & $1,110.6$ & 1.384 & 38.4 & 100.0 & 0.0 \\
\hline 10 & $1,045.5$ & $1,045.5$ & 770.5 & $1,454.6$ & 1.310 & 31.0 & 100.0 & 0.0 \\
\hline 11 & $1,381.0$ & $1,381.0$ & 696.9 & $1,815.3$ & 1.248 & 24.8 & 100.0 & 0.0 \\
\hline 12 & $1,737.1$ & $1,737.1$ & 618.7 & $2,174.3$ & 1.198 & 19.8 & 100.0 & 0.0 \\
\hline 13 & $2,095.6$ & $2,095.6$ & 540.0 & $2,516.7$ & 1.157 & 15.7 & 100.0 & 0.0 \\
\hline 14 & $2,440.9$ & $2,440.9$ & 464.2 & $2,832.0$ & 1.125 & 12.5 & 100.0 & 0.0 \\
\hline 50 & $4,550.2$ & $4,550.2$ & 1.2 & $4,550.4$ & 1.000 & 0.0 & 100.0 & 0.0 \\
\hline 51 & $4,550.4$ & $4,550.4$ & 1.1 & $4,550.5$ & 1.000 & 0.0 & 100.0 & 0.0 \\
\hline 52 & $4,550.5$ & $4,550.5$ & 1.1 & $4,550.6$ & 1.000 & 0.0 & 100.0 & 0.0 \\
\hline
\end{tabular}

Source: own elaboration.

\section{Comment}

The stock converges to the target level in about the 50th week. It could be treated as a success, but it should be noted at what expense - the price decreases almost to zero, which causes an enormous demand increase, which anyway is satisfied from the ongoing deliveries. This simulation can describe a case when a product has a fixed sell-out deadline defined by its life cycle, and is going to be replaced by a successor (new product, new version). The great demand that increased thanks to a low price, may be not kept at the same level when the price of the successor will be set back to the original price. The reasonable explanation for following such a scenario is the willingness for the immediate sell-out of a product with some faults: small damages or approaching an expiry date. 


\section{Simulation no. 3 - end of sales and complete sell-out}

In this case, a retailer wants to get rid of stock regardless of the lower incomes due to a price decrease. This case requires an assumption that deliveries are neither planned nor delivered. In order to model such a business case, one needs to set the initial value of the demand forecast to zero: $D^{\prime}{ }_{0}=0$, and exponential smoothing coefficient to zero as well: $\alpha=0$. Then, as noticed earlier, the real demand will not influence the demand forecast, and, by that, neither the deliveries. The set of input data for such a scenario are presented in Table 5, and its results - in Table 6 and in Figure 4.

Table 5. Input data for simulation no. 3

\begin{tabular}{|l|r|l|}
\hline \multirow{4}{*}{ Initial conditions } & $S_{0}=$ & 1,000 \\
\cline { 2 - 3 } & $D_{0}^{\prime}=$ & 0 \\
\cline { 2 - 3 } & $D_{0}=$ & 10 \\
\cline { 2 - 3 } & $p_{0}=p_{t}=$ & 100 \\
\hline$T=$ & 1 \\
\hline$\alpha=$ & 0 \\
\cline { 2 - 3 } & $a=$ & 0.7 \\
\cline { 2 - 3 } & $q=$ & $1,428.0$ \\
\cline { 2 - 3 } & $k=$ & 0.11 \\
\cline { 2 - 3 } & &
\end{tabular}

Source: own elaboration.

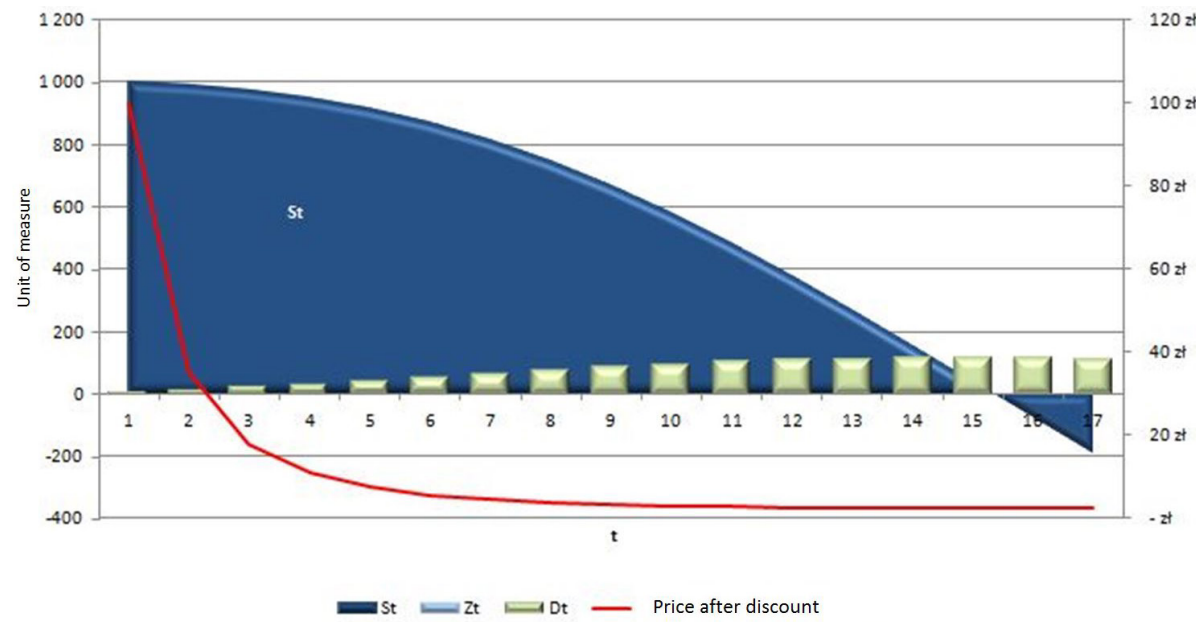

Figure 4. Graphical results of Simulation no. 3

Source: own elaboration. 
Table 6. Numerical results of simulation no. 3

\begin{tabular}{|c|c|c|c|c|c|c|c|c|}
\hline$t$ & $D_{t}^{\prime}$ & $Z_{t}$ & $S_{t}$ & $D_{t}$ & $\begin{array}{l}\text { Coefficient } \\
1 /\left(1-r_{t} / a\right)^{k}\end{array}$ & $\begin{array}{c}\text { Discount } \\
(\%)\end{array}$ & $\begin{array}{c}\text { Cumulated } \\
\text { discount } \\
(\%)\end{array}$ & $\begin{array}{c}\text { Price after } \\
\text { discount } \\
\text { (PLN) }\end{array}$ \\
\hline 0 & 0.0 & 0.0 & $1,000.0$ & 10.0 & & 0.0 & & 100.0 \\
\hline 1 & 0.0 & 0.0 & 990.0 & 16.5 & 1.649 & 64.9 & 64.9 & 35.1 \\
\hline 2 & 0.0 & 0.0 & 973.5 & 24.5 & 1.487 & 48.7 & 82.0 & 18.0 \\
\hline 3 & 0.0 & 0.0 & 949.0 & 34.0 & 1.385 & 38.5 & 88.9 & 11.1 \\
\hline 4 & 0.0 & 0.0 & 915.0 & 44.5 & 1.310 & 31.0 & 92.4 & 7.6 \\
\hline 5 & 0.0 & 0.0 & 870.5 & 55.7 & 1.251 & 25.1 & 94.3 & 5.7 \\
\hline 6 & 0.0 & 0.0 & 814.8 & 67.0 & 1.203 & 20.3 & 95.4 & 4.6 \\
\hline 7 & 0.0 & 0.0 & 747.7 & 78.0 & 1.163 & 16.3 & 96.2 & 3.8 \\
\hline 8 & 0.0 & 0.0 & 669.7 & 88.1 & 1.129 & 12.9 & 96.7 & 3.3 \\
\hline 9 & 0.0 & 0.0 & 581.7 & 96.9 & 1.100 & 10.0 & 97.0 & 3.0 \\
\hline 10 & 0.0 & 0.0 & 484.8 & 104.2 & 1.075 & 7.5 & 97.2 & 2.8 \\
\hline 11 & 0.0 & 0.0 & 380.5 & 109.9 & 1.054 & 5.4 & 97.4 & 2.6 \\
\hline 12 & 0.0 & 0.0 & 270.7 & 113.7 & 1.035 & 3.5 & 97.5 & 2.5 \\
\hline 13 & 0.0 & 0.0 & 157.0 & 115.9 & 1.019 & 1.9 & 97.5 & 2.5 \\
\hline 14 & 0.0 & 0.0 & 41.1 & 116.4 & 1.005 & 0.5 & 97.5 & 2.5 \\
\hline 15 & 0.0 & 0.0 & -75.3 & 115.4 & 0.992 & -0.8 & 97.5 & 2.5 \\
\hline 16 & 0.0 & 0.0 & -190.7 & 113.2 & 0.981 & -1.9 & 97.5 & 2.5 \\
\hline
\end{tabular}

Source: own elaboration.

\section{Comment}

We can observe that offering such a discount that the price decreases to reach 2.5 PLN, the stock of 1000 pieces can be sold out within 15 weeks. The negative number of stock informs that there is still a demand for the product, but it is not satisfied either from the stock or from the oncoming deliveries. The business case described in this simulation is the most realistic one, and the most probable to be applied in reality. It depicts the final phase of the product life cycle, when the decision about the end of sales and the as-soon-as-possible sell-out has been made.

\section{Real business data}

In Figure 5, the graph of the real data of demand, deliveries, and stock of a product of a big Polish production-trade food industry is presented. We present the data in order to compare them to the data produced by the model presented above, and, by that, to question the applicability of theoretical models to the real business data, which usually include some stochastic coefficient, 
and are not easy to describe with deterministic models. Nevertheless, mathematical models are assumed to describe reality with some simplifications and assumptions, therefore, the studied model can be a good starting point for modelling of microeconomics phenomena.

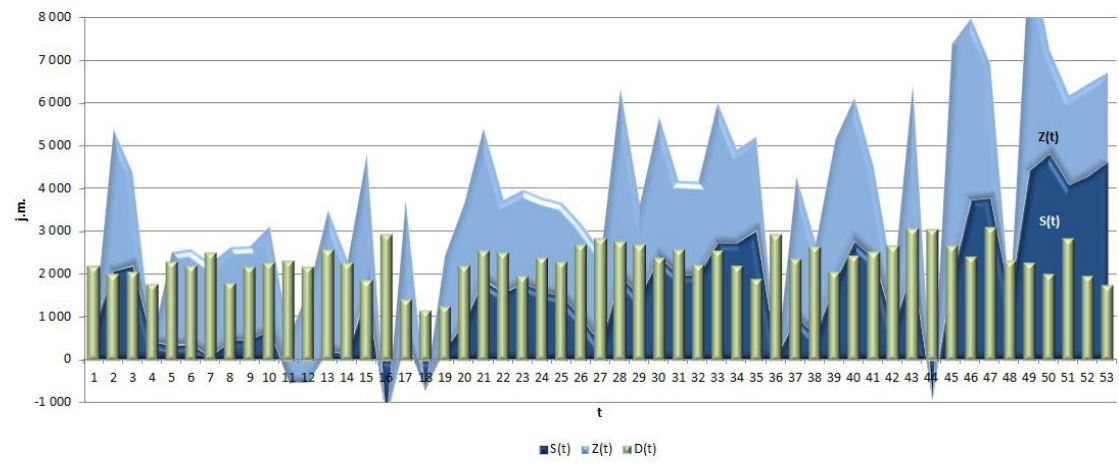

Figure 5. Real data of demand, deliveries, and stock of a product of a big Polish productiontrade food industry

Source: own elaboration.

\section{Conclusions}

In the paper, we have studied the mathematical model of demand and inventory from the perspective of its applications in real business cases. Originally, the model has been proposed in a mathematical journal. The authors commenced the studies on mathematical properties such as a stability of solutions and chaotic behaviour, and the primary results have been presented in Hachuła, Schmeidel (2015), followed by Hachuła, Nockowska-Rosiak, Schmeidel (2016), with the application of firm mathematical tools of a dynamical systems theory. A particular application of the model to the electrical energy market has been presented in Nowakowska (2015). Within this paper, with the support of computer simulations, three scenarios of applications have been presented, analysed, and commented upon. The most realistic scenario has been indicated. However, in contrary, we have recalled the real business data in order to underline that the model is a simplified image of reality. Nevertheless, in our opinion, the presented model is a good example of a compromise between the relative simplicity of mathematical methods and the applicability to the reality, and can be subject of further analyses from both a mathematical and economical perspective. 


\section{Technical notes and remarks}

The simulations have been performed in MS Excel 2010. The tables and graphs with the results have been prepared in MS Excel 2010. All the figures and tables are own elaborations, unless stated otherwise.

\section{References}

Brown, R.G. (1959). Statistical Forecasting for Inventory Control. New York: McGraw-Hill.

Hachuła, P., Schmeidel, E. (2015). Stability Analysis of Demand-Inventory Modeling a Certain Business Case, in Transcom Proceedings, 22-24 June 2015 (CD), University of Zilina.

Hachuła, P., Nockowska-Rosiak, M., Schmeidel, E. (2016). Stability of Equilibrium Points of Demand-Inventory Model with Stock-Dependent Demand. Journal of Difference Equations and Applications. DOI: 10.1080/10236198.2016.1208188.

Iskra, E., Woźniak, K. (2014). Cykl życia produktu. Encyklopedia zarządzania. Available at: http://mfiles.pl/pl/index.php/Cykl_zycia_produktu (access: 18.08.2015).

Krzyżaniak, S., Cyplik, P. (2008). Zapasy i magazynowanie, tom I - Zapasy. Poznań: Institute of Logistics and Warehousing.

Ma, J., Feng, Y. (2008). The Study of the Chaotic Behaviour in Retailer's Demand Model. Discrete Dynamics in Nature and Society. DOI: 10.1155/2008/792031.

Metzlar, A. (1941). The nature and stability of inventory cycles. The Review of Economic Statistics, 3 (23), 113-129.

Nowakowska, L. (2015). Dynamic discrete model for electricity price forecasting, 5th International Youth Conference on Energy, 27-30 May 2015, Pisa. DOI: 10.1109/ IYCE.2015.7180798.

Sarjusz-Wolski, Z. (2000). Sterowanie zapasem w przedsiębiorstwie. Warszawa: Polskie Wydawnictwo Ekonomiczne.

Wagner, H.M., Whitin, T.M. (1958). A dynamic version of the economic lot size model. Management Science, 10, 89-96. 